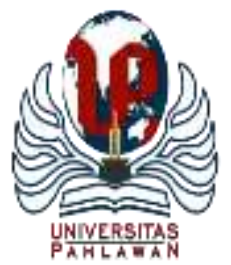

Edukatif : Jurnal Ilmu Pendidikan Volume 3 Nomor 6 Tahun 2021 Halm 4198 - 4206 EDUKATIF: JURNAL ILMU PENDIDIKAN

Research \& Learning in Education

https://edukatif.org/index.php/edukatif/index

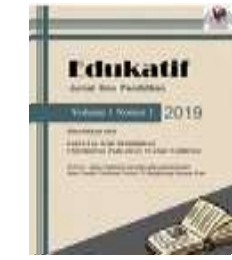

\title{
Pemanfaatan Media Buku Labaca Halfik (Lancar Membaca, Hafal Dan Fikir) dalam Meningkatkan Kemampuan Membaca Anak Usia 5-6 Tahun
}

\author{
Iif Nur Kholifah ${ }^{1}$, Astuti Darmiyanti ${ }^{2 凶}$, Nancy Riana ${ }^{3}$
}

Universitas Singaperbangsa Karawang, Indonesia ${ }^{1,2,3}$

E-mail : $\underline{\text { uminurkholifah123@ gmail.com }}{ }^{1}$, astuti.darmiyanti@ fai.unsika.ac.id ${ }^{2}$, nancy.riana@ $@$ fai.unsika.ac.id $^{3}$

\begin{abstract}
Abstrak
Tujuan penelitian adalah untuk mengetahui peningkatan kemampuan membaca anak melalui pemanfaatan media buku Labaca Halfik. Penelitian merupakan studi kuasi eksperimen dengan satu kelas eksperimen tanpa kelas kontrol (One Group Pretest-Posttest Design). Sampel penelitian 20 anak usia 5-6 tahun di TKQ An-Nur Halfik Karawang. Instrumen penelitiaan berupa lembar penilaian kemampuan membaca anak. Pengumpulan data dengan melakukan penilaian pretest dan post test kemampuan membaca. Analisis data berupa uji beda rata-rata dan uji normalisasi peningkatan N-Gain. Hasil penelitian menunjukkan uji beda rata-rata diperoleh nilai signifikansi (sig. 0,000$)<\alpha 0,05$ dengan $\mathrm{T}_{\text {hitung }}=8,163>\mathrm{T}_{\text {tabel }}=$ 2,093 menunjukkan media Labaca Halfik efektif meningkatakan kemampuan membaca. Uji normalisasi peningkatan kemampuan membaca antara pretest dan post test dengan nilai $\mathrm{N}$-gain 0,81 menunjukkan adanya peningkatan tinggi. Media buku LaBaCa HalFik menjadikan pembelajaran membaca lebih sistematis dan terkontrol. Guru maupun orang tua di rumah dapat melakukan kontrol dan mengetahui sejauh mana perkembangan kemampuan membaca. Pembelajaran dengan media buku LaBaCa Halfik menjadikan pembelajaran lebih menyenangkan dan melatih anak untuk mengembangkan kedisiplinan, kepercayaan diridan kemandirian belajar.
\end{abstract}

Kata Kunci: Media, Kemampuan Membaca, Anak Usia Dini.

\begin{abstract}
The purpose of the study was to determine the improvement of children's reading skills through the use of the Laba Halfik book media. This research is a quasi-experimental study with one experimental class without a control class (One Group Pretest-Posttest Design). The research sample was 20 children aged 5-6 years at TKQ An-Nur Halfik Karawang. The research instrument is an assessment of children's reading ability. Collecting data by conducting pretest and posttest assessment of reading ability. Data analysis was in the form of average difference test and normalization test for increasing N-Gain. The results showed that the average difference test obtained a significance value (sig. 0.000$)<0.05$ with Tcount $=8.163>$ Ttable $=2.093$ indicating that the Labaca Halfik media was effective in increasing reading ability. The normalization test of increasing reading ability between pretest and posttest with an $N$-gain value of 0.81 indicates an increase in height. HalFik's LaBaCa book media makes reading learning more systematic and controlled. Teachers and parents at home can control and know how far the development of reading skills. Learning with the LaBaCa Halfik book media makes learning more fun and trains children to develop discipline, self-confidence and learning independence.
\end{abstract}

Keywords: Media, Reading Ability, Early Childhood

Copyright (c) 2021 lif Nur Kholifah, Astuti Darmiyanti, Nancy Riana

$\triangle$ Corresponding author

Email : astuti.darmiyanti@fai.unsika.ac.id

DOI : https://doi.org/10.31004/edukatif.v3i6.1425

ISSN 2656-8063 (Media Cetak)

ISSN 2656-8071 (Media Online) 
4199 Pemanfaatan Media Buku Labaca Halfik (Lancar Membaca, Hafal Dan Fikir) dalam Meningkatkan Kemampuan Membaca Anak Usia 5-6 Tahun - Iif Nur Kholifah, Astuti Darmiyanti, Nancy Riana DOI: https://doi.org/10.31004/edukatif.v3i6.1425

\section{PENDAHULUAN}

Anak usia dini(AUD) diakui oleh banyak ahli perkembangan anak sebagai masa emas (golden age). Masa ini memberkan sangat banyak pengaruh bagi pertumbuhan dan perkembangan anak. Pembelajaran yang dilakukan anak pada usia dini berperan penting dalam mewujudkan keberhasilan tumbuh kembang anak di masa mendatang (Wulansuci, 2021). Berbagai perkembangan seperti keterampilan, kreativitas dan kreativitas serta pematangan fungsi fisik maupun psiklogis terjadi di masa golden age ini (Hayati, 2020). Oleh karena itu penting bagi guru dan orang tua memfasilitasi anak agar dapat mengoptimalkan berbagai aspek perkembangan diri mencakup kognitif, motorik, afektif, fisik, daan bahasa (Suyadi \& Ulfah, 2015).

Pada anak usia 5-6 tahun, kemampuan membaca menjadi salah satu aspek perkembangan anak yang perlu dikembangkan (Irdawati; Yunidar; dan Darmawan, 2017). Membaca memiliki fungsi dan peran penting yang membedakan manusia dengan makhluk lainnya, sehingga pantas jika membaca menjadi aspek keterampilan tertinggi terkait fungsi kemanusiaan (Hadini, 2017). Di era modern dengan tingkat literasi yang tinggi, membaca juga dapat menajdi indikator kualitas seorang individu (Trimantara \& Mulya, 2019). Dengan kualitas dan kuantitas membaca yang baik, dapat menambah wawasan, ilmu pengetahuan, kebijaksanaan, dan pengalaman (Yunitasari \& Hanifah, 2020). Membaca dapat menjadikan anak memiliki nilai-nilai yang lebih jika dibandingkan dengan anak yang malas atau bahkan tidak membaca sama sekali (Latifah, 2019).

Seiring dengan tuntutan kebutuhan keterampilan literasi membaca di sekolah dasar, perdebatan mengenai pengajaran membaca pada jenjang pendidikan usia dini pun kian diperdebatkan (Matin et al., 2019). Sejauh ini belum ada regulasi yang secara tegas mengharuskan bisa membaca bagi anak pra-sekolah, bahkan para ahli pendidikan anak sebagian mengecam perampasan hak anak usia dini akibat pemaksaan penguasaan keterampilan yang menuntut anak belajar dengan keras (Boyd \& Newman, 2019). Padahal dunia anak merupakan dunia bermain dan mengembangkan keterampilan sesuai tugas perkembangannya (Novita, 2018). Dampak miskonsepsi sebagian masyarakat mengenai kemampuan membaca inilah yang kemudian melahirkan sebuah tuntutan sosial dimana sebagian besar orang tua menuntut agar anak-anak mereka memiliki kemampuan membaca yang baik sebelum memasuki jenjang pendidikan dasar (Patiung, 2016).

Sampai saat ini, polemik dan pro-kontra tentang pembelajaran membaca diajarkan pada anak sejak dini masih menimbulkan keraguan di kalangan praktisi pendidikan anak (Srijatun, 2017). Ada sebagian ahli yang menilai bahwa pengajaran membaca yang diajarkan membuat anak menjadi tertekan (Anggidesialamia, 2020). Pandangan ini didasarkan pada asumsi bahwa anak belum memiliki kesiapan belajar membaca di usia dini. Namun ada pula sebagian ahli pendidikan modern yang justru mendukung pembelajaran baca perlu diajarkan sejak dini pada anak (Trimantara \& Mulya, 2019). Menurut mereka membaca mutlak dimiliki anak karena merupakan skill yang akan mendukung keberlangsungan anak pada tahapan perkembangan selanjutnya (Edi Widianto, 2015). Mereka para ahli modern ini beranggapan bahwa ketidak mampuan membaca akan berdampak terhambatnya proses belajar anak di masa mendatang (Herlina, 2019).

Soetjiningsih (2012) dalam penelitiannya menjelaskan adanya keterkaitan erat antara kemampuan membaca dengan kemampuan berbahasa yang merupakan salah satu indikator perkembangan anak. Pada usia 5-6 tahun merupakan tahapan membaca bridging reading stage pada anak. Mereka memiliki kesadaran dan sensitivitas yang baik mengenai simbol tulisan atau keaksaraan yang nampak di sekitar mereka. Hal yang penting disadari adalah bahwa belajar membaca bukanlah hal instan bagi anak, oleh dibutuhkan waktu yang berkelanjutan, ketelatenan, kesiapan, dan kesabaran (Hariandi, 2019). Hasan Lubis \& Darwis Dasopang (2020) mengemukakan pada sebagian anak yang menyukai simbol, gambar dan huruf sejak awal perkembangan, menjadi modal dasar yang positif sehingga mereka memiiki minat membaca yang baik dan belajar dengan cara yang menyenangkan.

Pada kenyataannya, anak usia 5-6 tahun memiliki perkembangan membaca yang bevariasi dan mengalami permasalahan masing-masing serta kendala dalam proses pembelajaran. Sebagaimana studi 
pendahuluan di TK An-Nur Halfik Klari kabupaten Karawang, masih terdapat anak usia 5-6 tahun yang mengalami kesulitan membaca. Observasi penulis menemukan secara klasikal kemampuan anak dalam mengenal dan menyebutkan simbol huruf berkembang sangat baik, namun masih didapati anak yang belum lancar membaca dua huruf yang membentuk suku kata (vokal dan konsonan), terbata-bata membaca kata dan kesulitan membaca satu kalimat pendek yang terdiri dari 2 atau 3 kata.

Kondisi demikian perlu diupayakan solusinya. Pemanfaatan media yang efektif perlu dipertimbangkan agar membantu anak memperkaya bahasa dan menambah kosa kata (TANU, 2019). Kendati tersedia banyak media yang mampu meningkatkan kemampuan membaca pada anak usia dini, namun pada situasi dan karakteristik anak yang berbeda tentu hasilnya akan berbeda pula (Cahyati, 2020). TKQ Nurul Halfik berupaya meningkatkan kemampuan membaca anak dengan memanfaatkan media buku bacaan LaBaCa HaLFik (lancar membaca Hafal dan Berfikir) yaitu sebuah media berbentuk buku yang diadaptasi dari pembelajaran membaca Al-Qur'an yang berisikan susunan huruf secara sistematis, suku kata, kata dan kalimat pendek yang secara berjenjang mengarahkan anak pada kemampuan membaca simbol, membaca suku kata, membaca kata, dan membaca susunan kata yang membentuk sebuah kalimat pendek.

Beberapa hasil penelitian mengkonfirmasi keberhasilan media buku dalam meningkatkan kemampuan membaca pada anak usia dini. Afrianti Yulia \& Wirman (2020) dalam penelitiannya menunjukkan bahwa media buku membantu menstimulasi kemampuan membaca anak dalam mengenal simbol dan bunyi huruf, merangakai huruf menjadi kata, serta merangkai kata menjadi kalimat sederhana yang bermakna. Sajawandi \& Rosalina (2020) dalam penelitiannya menjelaskan bahwa media buku membantu meningkatkan kemampuan membaca anak, menjadikan pembelajaran membaca lebih sistematis dan mudah terkontrol sehingga orang tua di rumah dapat mengetahui persissampai dimana perkembangan kemampuan membaca anak.

Pada penelitian ini, dilakukan sebuah eksperimen media buku bacaan LaBaCa HaLFik (lancar membaca Hafal dan Berfikir) pada siswa 5-6 tahun di TKQ Nurul Halfik Karawang. Media buku ini tergolong masih baru dan menjadi ciri khas pembelajaran membaca di TKQ Nurul Halfik. Diharapkan melalui pemanfaatan media buku bacaan LaBaCa HaLFik mampu meningkatkan kemampuan membaca anak usia 5-6 tahun.

\section{METODE PENELITIAN}

Pada penelitian ini digunakan metode kuasi eksperimen dengan desain satu kelas saja (One Group Pretest-Posttest Design) (Sugiyono, 2016). Desain tersebut dipilih karena keterbatasan sampel sehingga penelitian hanya memungkinkan dilaksanakan dengan satu kelas eksperimen tanpa kelas kontrol/pembanding (Creswell, 2014). Sampel penelitian sebanyak 20 anak usia 5-6 tahun di TKQ Nurul Halfik Karawang. Instrumen pengumpulan data penelitian menggunakan lembar penilaian kemampuan membaca. Analisis data menggunakan uji beda rata-rata (Paired Sample T-Test) dan uji normalisasi Gain (N-Gain) untuk mengetahui tingkat peningkatan kemampuan membaca dengan formula N-Gain sebagai berikut(Asmawati, 2020):

Keterangan:

\begin{tabular}{c}
$\mathrm{G}=(\mathrm{N}$ post - N Pre $)$ \\
\hline (N Max - N Pre $)$
\end{tabular}

$\mathrm{G}=$ Rata-rata peningkatan $(0,00-1,00)$

$\mathrm{N}$ Post $=$ Rata-rata posttest

$\mathrm{N}$ Pre $=$ Rata-Rata pretest

$\mathrm{N}$ Max = Nilai maksimal yang diisyaratkan 
4201 Pemanfaatan Media Buku Labaca Halfik (Lancar Membaca, Hafal Dan Fikir) dalam Meningkatkan Kemampuan Membaca Anak Usia 5-6 Tahun - Iif Nur Kholifah, Astuti Darmiyanti, Nancy Riana DOI: https://doi.org/10.31004/edukatif.v3i6.1425

Hasil nilai $\mathrm{N}$-gain yang diperoleh akan dikonsultasikan dengan pedoman interprestasi Gain sebagai berikut (Patmawati et al., 2018):

Tabel 1. Interprestasi Nilai Gain

\begin{tabular}{ll}
\hline Interval & Interprestasi \\
\hline$<0,3$ & Rendah \\
\hline $0,3-0,7$ & Sedang \\
\hline \multicolumn{1}{c}{0,7} & Tinggi \\
\hline
\end{tabular}

Untuk mengetahui deskripsi mengenai skor hasil pretest dan post test kemampuan membaca anak, digunakan penilaian dan pengukuran berdasarkan nilai angka dan huruf sebagai berikut (Kejora, 2020):

Tabel 2. Prosentase dan Kriteria Penilaian

\begin{tabular}{|c|c|c|c|}
\hline \multicolumn{2}{|c|}{ Simbol Nilai Angka Dan Huruf } & \multirow{2}{*}{\multicolumn{2}{|c|}{ Predikat }} \\
\hline Skala & Angka (\%) & & \\
\hline $0,01-1,49$ & $0,01-37,25$ & $\mathrm{BB}$ & Belum Berkembang \\
\hline $1,50-2,49$ & $37,26-62,26$ & MB & Mulai Berkembang \\
\hline $2,50-3,49$ & $62,27-87,49$ & BSH & $\begin{array}{l}\text { Berkembanag Sesuai } \\
\text { Harapan }\end{array}$ \\
\hline $3,50-4,00$ & $87,5-100$ & BSB & $\begin{array}{ll}\text { Berkembang } \\
\text { Baik }\end{array}$ \\
\hline
\end{tabular}

\section{HASIL DAN PEMBAHASAN PENELITIAN}

\section{Kemampuan Membaca Awal (Pre-Test)}

Pada tahap awal sebelum diberikan treatment dilakukan penilaian kemampuan membaca anak. Siswa membaca teks yang guru berikan tanpa ada intervensi atau bantuan apapun dan guru sebatas melakukan penilaian kemampuan membaca. Kemampuan membaca yang diukur mencakup 4 aspek: 1) kemampuan mengenal dan menyebutkan lambang huruf, 2) kemampuan membaca suku kata (vokal dan konsonan), 3) kemampuan membaca kata, dan 4) kemampuan membaca satu kalimat sederhana yang terdiri dari 2 atau 3 suku kata.

Tabel 3. Pretest Kemampuan Membaca

\begin{tabular}{|c|c|c|c|c|}
\hline \multirow{3}{*}{ No } & \multirow{3}{*}{ Aspek } & \multicolumn{3}{|c|}{ Jumlah } \\
\hline & & Hasil & Anak & Rata Rata \\
\hline & & & Pretest & \\
\hline \multirow{4}{*}{1} & \multirow{4}{*}{$\begin{array}{l}\text { Mengenal dan menyebutkan } \\
\text { lambang huruf }\end{array}$} & $\mathrm{BB}$ & 0 & \multirow{4}{*}{2,80} \\
\hline & & MB & 10 & \\
\hline & & $\mathrm{BSH}$ & 4 & \\
\hline & & BSB & 6 & \\
\hline \multirow{4}{*}{2} & \multirow{4}{*}{$\begin{array}{l}\text { Kemampuan membaca suku } \\
\text { kata }\end{array}$} & $\mathrm{BB}$ & 3 & \multirow{4}{*}{2,45} \\
\hline & & MB & 9 & \\
\hline & & BSH & 4 & \\
\hline & & BSB & 4 & \\
\hline \multirow{4}{*}{3} & \multirow{4}{*}{ Kemampuan membaca kata } & $\mathrm{BB}$ & 7 & \multirow{4}{*}{2,15} \\
\hline & & MB & 7 & \\
\hline & & BSH & 2 & \\
\hline & & BSB & 4 & \\
\hline \multirow{4}{*}{4} & \multirow{4}{*}{$\begin{array}{l}\text { Kemampuan membaca satu } \\
\text { kalimat sederhana }\end{array}$} & $\mathrm{BB}$ & 7 & \multirow{4}{*}{2,10} \\
\hline & & MB & 7 & \\
\hline & & BSH & 3 & \\
\hline & & BSB & 3 & \\
\hline
\end{tabular}


4202 Pemanfaatan Media Buku Labaca Halfik (Lancar Membaca, Hafal Dan Fikir) dalam Meningkatkan Kemampuan Membaca Anak Usia 5-6 Tahun - Iif Nur Kholifah, Astuti Darmiyanti, Nancy Riana DOI: https://doi.org/10.31004/edukatif.v3i6.1425

\begin{tabular}{llll}
\hline \multirow{2}{*}{ No Aspek } & \multicolumn{2}{c}{$\begin{array}{l}\text { Jumlah } \\
\text { Hasil }\end{array}$} & $\begin{array}{l}\text { Anak } \\
\end{array}$ \\
& & Pretest & \\
\hline Rata-rata & MB & - & 2,38 \\
\hline
\end{tabular}

Berdasarkan hasil pretest diketahui bahwa pada tahap awal (pretest) kemampuan anak dalam mengenal dan menyebutkan lambang huruf mulai bertkembang $(2,80)$. Kemampuan anak dalam membaca suku kata mulai berkembang $(2,45)$. Kemampuan anak dalam membaca kata mulai berkembang $(2,15)$. Dan kemampuan anak membaca kalimat sederhana mulai berkembang $(2,10)$

Rata-rata kemampuan membaca anak secara klasikal pada fase pretest sebesar 2,38 menunjukkan bahwa secara umum kemampuan membaca anak mulai berkembang.

\section{Kemampuan Membaca Akhir (Post-Test)}

Setelah mengetahui kemampuan membaca awal (pretest) dilakukan perencanaan dan pelaksanaan pembelajaran dengan memanfaatkan media buku LaBaCa HalFik. Penggunaan buku LaBaCa HalFik dalam meningkatkan kemampuan membaca anak diimplementasikan secara klasikal maupun secara klinis atau individual.
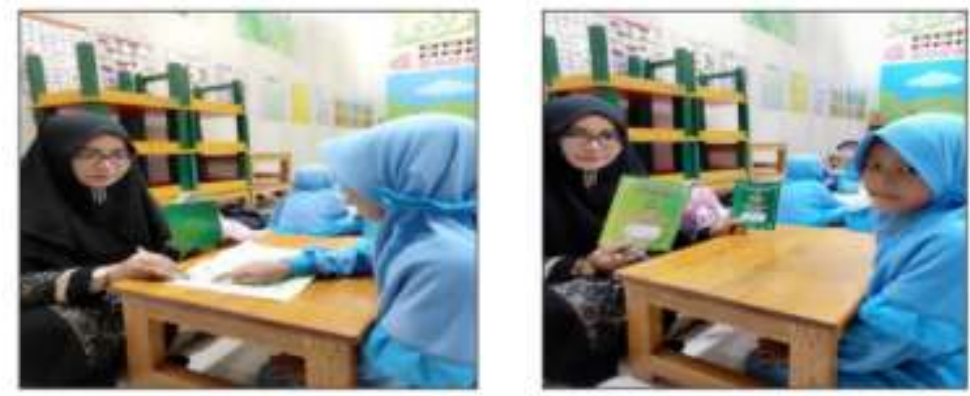

\section{Gambar 1. Pembelajaran Membaca Secara Privat dan Klinis}

Satu jam sebelum pembelajaran membaca di mulai secara klasikal, setiap siswa diberikan kesempatan secara individual untuk belajar membaca. Siswa yang lebih awal datang akan memperoleh kesempatan lebih awal menyelesaikan pembelajaran secara individual.
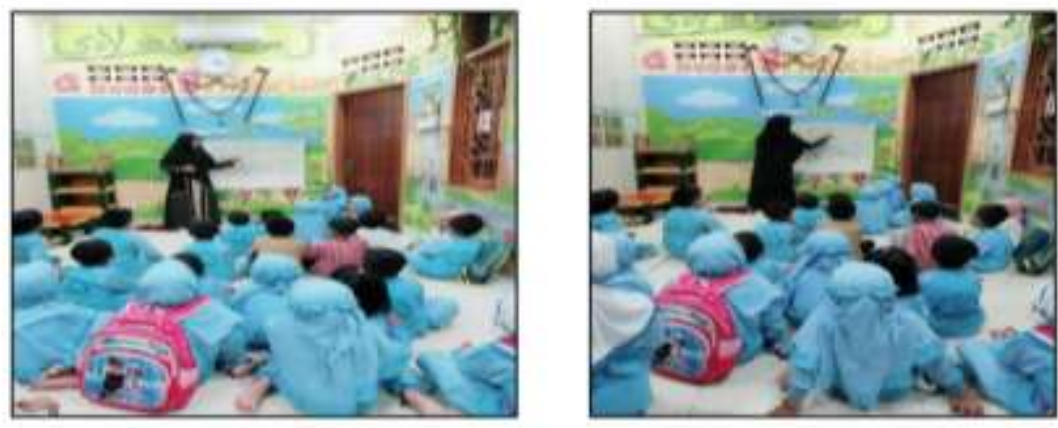

Gambar 2. Pembelajaran Membaca Secara Klasikal

Pembelajaran dengan memanfaatkan media buku LaBaCa HalFik memberi kesempatan kepada anak meningkatkan kemampuan membaca secara berkelanjutan dan bertahap. Anak belajar mengenal dan menyebutkan lambang huruf, membaca suku kata, membaca kata, dan membaca satu kalimat sederhana. 


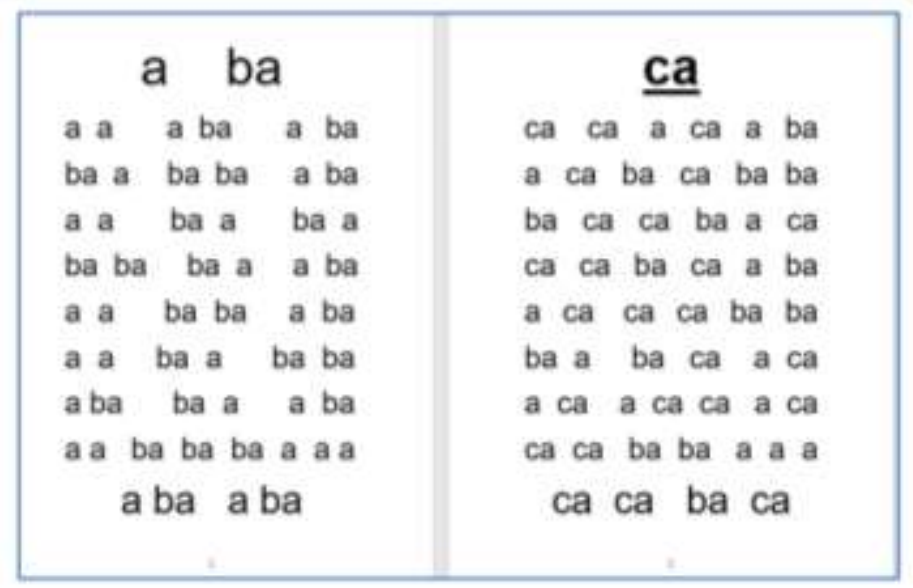

Gambar 3. Buku LaBaCa HalFik

Selama proses pembelajaran dilakukan observasi dan di akhir dilakukan penilaian kemampuan membaca siswa.

Tabel 4. Posttest Kemampuan Membaca

\begin{tabular}{|c|c|c|c|c|}
\hline \multirow{2}{*}{ No } & \multirow{2}{*}{ Aspek } & \multirow{2}{*}{ Hasil } & Jumlah Anak & \multirow{2}{*}{ Rata Rata } \\
\hline & & & Pretest & \\
\hline \multirow{4}{*}{1} & \multirow{4}{*}{$\begin{array}{l}\text { Mengenal dan } \\
\text { menyebutkan lambang } \\
\text { huruf }\end{array}$} & $\mathrm{BB}$ & 0 & \multirow{4}{*}{4,00} \\
\hline & & $\mathrm{MB}$ & 0 & \\
\hline & & $\mathrm{BSH}$ & 0 & \\
\hline & & BSB & 20 & \\
\hline \multirow{4}{*}{2} & \multirow{4}{*}{$\begin{array}{l}\text { Kemampuan membaca } \\
\text { suku kata }\end{array}$} & $\mathrm{BB}$ & 0 & \multirow{4}{*}{3,80} \\
\hline & & $\mathrm{MB}$ & 0 & \\
\hline & & $\mathrm{BSH}$ & 4 & \\
\hline & & BSB & 16 & \\
\hline \multirow{4}{*}{3} & \multirow{4}{*}{$\begin{array}{l}\text { Kemampuan membaca } \\
\text { kata }\end{array}$} & $\mathrm{BB}$ & 0 & \multirow{4}{*}{3,65} \\
\hline & & $\mathrm{MB}$ & 0 & \\
\hline & & $\mathrm{BSH}$ & 7 & \\
\hline & & BSB & 13 & \\
\hline \multirow{4}{*}{4} & \multirow{4}{*}{$\begin{array}{l}\text { Kemampuan membaca } \\
\text { satu kalimat sederhana }\end{array}$} & $\mathrm{BB}$ & 0 & \multirow{4}{*}{3,35} \\
\hline & & $\mathrm{MB}$ & 2 & \\
\hline & & BSH & 8 & \\
\hline & & BSB & 10 & \\
\hline \multicolumn{2}{|c|}{ Rata-rata } & BSB & - & 3,70 \\
\hline
\end{tabular}

Berdasarkan hasil diketahui bahwa pada tahap akhir (posttest) setelah diberikan treatment pembelajaran dengan memanfaatkan media buku LaBaCa HalFik kemampuan anak dalam mengenal dan menyebutkan lambang huruf berkembang sangat baik $(4,00)$ dan $100 \%$ anak mampu menguasai. Kemampuan anak dalam membaca suku kata berkembang sangat baik $(3,80)$. Kemampuan anak dalam membaca kata berkembang sangat baik $(3,65)$. Dan kemampuan anak membaca kalimat sederhana betrkembang sesuai harapan $(3,35)$.

Rata-rata kemampuan membaca anak secara klasikal pada fase post test sebesar 3,70 menunjukkan bahwa secara umum kemampuan membaca anak berkembang sangat baik.

\section{Peningkatan Kemampuan Membaca Anak}

Setelah data pretest dan post test terkumpul, dilakukan analisis deskriptif dan interprestasi pencapaian pembelajaran. Setelah itu, untuk mengetahui pengaruh media buku LaBaCa HalFik dilakukan uji beda ratarata dan uji normalisasi Gain. 
Tahap awal adalah melakukan uji asumsi klasik berupa uji normalitas dan uji homogenitas data.

\section{Tabel 5. Uji Persyaratan Analisis}

\begin{tabular}{lllll}
\hline \multirow{2}{*}{ Kelas } & \multicolumn{2}{l}{ Uji Normalitas } & \multicolumn{2}{l}{ Uji Homogenitas } \\
\cline { 2 - 5 } & Sig & $\begin{array}{l}\text { Distribusi } \\
\text { Data N-gain }\end{array}$ & Sig & $\begin{array}{l}\text { Variansi Data } \\
\text { Kedua Kelas }\end{array}$ \\
\hline Pretest & 0.313 & Normal & 0.122 & Homogen \\
\hline Posttets & 0.192 & Normal & &
\end{tabular}

Hasil uji normalitas dan uji homogenitas menunjukkan bahwa kedua data memenhi distribusi normal dan homogen. Dengan demikian pengujian beda rata-rata menggunaka uji parametrik menggunakan uji Paired Sample T-Test. Berdasarkan uji beda rata-rata diperoleh nilai signifikansi (sig. 0,000$)<\alpha \quad 0,05$ dengan $\mathrm{T}_{\text {hitung }}$ $=8,163>\mathrm{T}_{\text {tabel }}=2,093$. Dengan demikian hasil uji beda rata-rata menunjukkan bahwa terdapat perbedaan rata-rata yang signifikan antara pretest dengan post test kemampuan membaca anak usia 5-6 tahun di TKQ An-Nur HalFik Karawang.

Tabel 6. Peningkatan Kemampuan Membaca

\begin{tabular}{llll}
\hline Pretest & Posttest & Peningkatan & N-Gain \\
\hline 2,38 & 3,70 & 1,33 & 0,82 \\
\hline
\end{tabular}

Mengacu pada hasil uji beda rata-rata, untuk mengetahui besar dan tingkat peningkatan kemampuan membaca nak, dilakukan uji normalisasi gain. Hasilnya menunjukkan terdapat peningkatan 1,33 poin dengan indeks $\mathrm{N}$-gain 0,82. Berdasarkan hasil uji beda rata-rata dan hasil uji normalisasi gain menunjukkan bahwa buku LaBaCa HalFik berpengaruh signifikan terhadap kemampuan membaca anak usia 5-6 tahun di TKQ AnNur HalFik dengan tingkat peningkatan 0,82 (tinggi).

Mengacu pada teori perkembangan Piaget, anak usia 5-6 tahun memiliki perkembangan kognitif praoperasional. Mereka memiliki pemikiran yang lebih banyak didasarkan atas pengalaman konkrit yang dialami dari pada pemikiran logis. Ketika anak melihat objek yang berbeda maka mereka akan mengatakan hal yang berbeda pula. Anak pada tahapan ini belum sepenuhnya mampu menguasai sebuah konsep secara utuh. Mereka juga belum mampu memahami dan berpikir tentang dua aspek atau lebih secara bersamaan.

Anak dengan usia 5-6 tahun memiliki pola pikir yang dibentuk berdasarkan pengalaman interaksi dan rangsangan atau stimulus yang diberikan oleh lingkungannya. Maka melalui pemanfaatan media buku LaBaCa HalFik mampu menghadirkan suasana pengalaman dan lingkungan belajar yang dapat merangsang perkembangan kognitif anak sesuai dengan tahapan dan kebutuhan tugas perkembangannya.

Hasil penelitian menunjukkan pemanfaatan media buku LaBaCa HalFik efektif meningkatkan kemampuan membaca pada anak. Efektifitas ini didukung oleh konten materi ajar pada buku yang membantu anak lebih mudah mengasah kemampuan membacanya. Dukungan lainnya adalah proses pembelajaran yang secara sistematis dan terukur mampu mengarahkan dan membimbing anak untuk mengenal dan menyebutkan lambang huruf, membaca suku kata, membaca kata, dan membaca satu kalimat sederhana

Hasil penelitian ini sejalan dengan hasil penelitian yang dilakukan Sajawandi \& Rosalina (2020) bahwa media buku memfasilitasi anak bermain literasi. Media buku menjadikan pembelajaran membaca lebih sistematis dan terkontrol. Guru maupun orang tua di rumah dapat melakukan kontrol dan mengetahui sejauh mana perkembangan kemampuan membaca anak. Untuk itu diperlukan komunikasi dan koordinasi antara guru dengan orang tua agar anak mampu meningkatkan kemampuan membaca secara optimal.

Temuan lain dari penelitian selain peningkatan kemampuan membaca adalah bahwa media buku LaBaCa HalFik perlu disempurnakan terutama pada aspek layout yang masih polos (uncolour). Anak memiliki kesukaan pada warna dan bentuk yang menarik sehingga membuat mereka lebih termotivasi untuk belajar. Untuk itu perlu didesain media buku yang lebih berwarna dengan berisikan gambar-gambar karakter anak sehingga lebih menarik dan kreatif bagi anak sehingga belajar menjadi lebih mnyenangkan dan tidak membosankan. Temuan lain penelitian adalah selain meningkatnya kemampuan membaca, aspek sosial 
4205 Pemanfaatan Media Buku Labaca Halfik (Lancar Membaca, Hafal Dan Fikir) dalam Meningkatkan Kemampuan Membaca Anak Usia 5-6 Tahun - Iif Nur Kholifah, Astuti Darmiyanti, Nancy Riana DOI: https://doi.org/10.31004/edukatif.v3i6.1425

emosional anak juga mengalami perkembangan seperti tumbuhnya kepercayaan diri dan kemandirian belajar anak. Temuan ini tentunya mendorong perlunya penelitian lebih lanjut dengan aspek lain yang belum diteliti secara mendalam karena keterbatasan penelitian.

\section{KESIMPULAN}

Pemanfaatan media buku LaBaCa HalFik efektif meningkatkan kemampuan membaca anak usia 5-6 tahun di TKQ An-Nur Halfik kabupaten Karawang. Secara sistematis dan bertahap anak mengalami kemajuan kemampuan membaca mencakup empat aspek yang diukur yaitu mengenal dan menyebutkan lambang huruf, membaca suku kata, membaca kata, dan membaca satu kalimat sederhana. Media buku LaBaCa HalFik menjadikan pembelajaran membaca lebih sistematis dan terkontrol. Guru maupun orang tua di rumah dapat melakukan kontrol dan mengetahui sejauh mana perkembangan kemampuan membaca. Anak dilatih bersikap tekun, teliti dan fokus terhadap pembelajaran. Melalui pembelajaran yang menyenangkan, aspek lain yang juga mengalami peningkatan melalui pemanfaatan media buku LABaCa Halfik adalah berkembangnya kedisiplinan, kepercayaan diri dan kemandirian belajar pada anak.

\section{DAFTAR PUSTAKA}

Afrianti Yulia, A., \& Wirman. (2020). Penggunaan Media Busy Book Untuk Menstmulasi Kemampuan Membaca Anak. Jurnal Pendidikan Tambusai, 4(2), 1156-1163.

Anggidesialamia, H. (2020). Upaya Meningkatkan Minat Baca Melalui Review Konten Cerita Rakyat Pada Aplikasi Youtube. Comm-Edu (Community Education Journal), 3(2), 75. Https://Doi.Org/10.22460/Comm-Edu.V3i2.3779

Asmawati, E., \& Bintang Kejora, M. T. (2020). The Effect Of Using Simple Aircraft Concrete Media On The Mastery Of Concepts In Inquiry Science Learning In Elementary School Students. Mudarrisa: Jurnal Kajian Pendidikan Islam, 12(2), 150-168. Https://Doi.Org/10.18326/Mdr.V12i2.150-168

Boyd, W., \& Newman, L. (2019). Primary + Early Childhood = Chalk And Cheese? Tensions In Undertaking An Early Childhood/Primary Education Degree. Australasian Journal Of Early Childhood, 44(1), 19-31. Https://Doi.Org/10.1177/1836939119841456

Cahyati, A. (2020). Pengembangan Aspek Bahasa Melalui Daring Selama Masa Pandemi Covid 19 Di Ra Nurul Huda. Jurnal Pendidikan Islam, 1-10.

Creswell, J. W. (2014). Research Design Qualitative, Quantitative, And Mixed Method Approaches. Sage Publication. Inc.

Edi Widianto. (2015). Peran Orang Tua Dalam Meningkatkan Pendidikan Karakter Anak Usia Dini Dalam Keluarga. Pg-Paud Trunojoyo, 2(1), 31-39.

Hadini, N. (2017). Meningkatkan Kemampuan Membaca Anak Usia Dini Melalui Kegiatan Permainan Kartu Kata Di Tk Al-Fauzan Desa Ciharashas Kecamatan Cilaku Kabupaten Cianjur. Jurnal Empowerment, 6(1), 19-24.

Hariandi, A. (2019). Strategi Guru Dalam Meningkatkan Keterampilan Membaca Alquran Siswa Di Sdit Aulia Batanghari. Jurnal Gentala Pendidikan Dasar, 4(1), 10-21. Https://Doi.Org/10.22437/Gentala.V4i1.6906

Hasan Lubis, A., \& Darwis Dasopang, M. (2020). Pengembangan Buku Cerita Bergambar Berbasis Augmented Reality Untuk Mengakomodasi Generasi Z. Jurnal Pendidikan: Teori, Penelitian, Dan Pengembangan, 05(06), 780-791. Https://Doi.Org/10.17977/Jptpp.V5i6.13613

Hayati, N. (2020). Peningkatan Kemampuan Membaca Permulaan Melalui Media Aism (Anak Islam Suka 
4206 Pemanfaatan Media Buku Labaca Halfik (Lancar Membaca, Hafal Dan Fikir) dalam Meningkatkan Kemampuan Membaca Anak Usia 5-6 Tahun - Iif Nur Kholifah, Astuti Darmiyanti, Nancy Riana DOI: https://doi.org/10.31004/edukatif.v3i6.1425

Membaca) Pada Siswa Tunadaksa Kelas Iv Slb N 1 Bantul. Exponential, 1(1), 27-36. Http://Dx.Doi.Org/10.1016/J.Carbpol.2016.12.050\%0a

Herlina, E. S. (2019). Membaca Permulaan Untuk Anak Usia Dini Dalam Era Pendidikan 4.0.Pionir; Jurnal Pendidikan, 5(4).

Irdawati; Yunidar; Dan Darmawan. (2017). Meningkatkan Kemampuan Membaca Permulaan Dengan Menggunakan Media Gambar Kelas 1 Di Min Buol, Issn 2354-614x. Jurnal Kreatif Tadulako Online, 5(4), 1-14. Http://Jurnal.Untad.Ac.Id/Jurnal/Index.Php/Jkto/Article/View/2918

Kejora, M. T. B. (2020). The Use Of Concrete Media In Science Learning In Inquiry To Improve Science Process Skills For Simple Machine Subject. Mudarrisa: Jurnal Kajian Pendidikan Islam, 12(1), 1-17. Https://Doi.Org/10.18326/Mdr.V12i1.1-17

Latifah, A. (2019). Pembuatan Dan Penggunaan Media Big Book Untuk Membentuk Anak Usia Dini Senang Membaca.Bunayya, Vi(2), 141-155.

Matin, R. H., Ety Rohaety, E., \& Nuraeni, L. (2019). Penerapan Media Pembelajaran Pop-Up Book Anak Usia Dini Pada Kelompok B Untuk Meningkatkan Kemampuan Keaksaraan Awal Di Tk Nusa Indah. Ceria (Cerdas Energik Responsif Inovatif Adaptif), 2(2), 49. Https://Doi.Org/10.22460/Ceria.V2i2.P49-56

Novita, A. (2018). Peran Orang Tua Dalam Menstimulasi Perkembangan Kognitif Anak Usia Dini. Attāalunā: Journal Of Islamic Early Childhood Education, 1(1), 11-19. Https://Doi.Org/10.32505/Atfaluna.V1i1.769

Patiung, D. (2016). Membaca Sebagai Sumber Pengembangan Intelektual. Al Daulah: Jurnal Hukum Pidana Dan Ketatanegaraan, 5(2), 352-376. Https://Doi.Org/10.24252/Ad.V5i2.4854

Patmawati, D., Ws, R., \& Halimah, M. (2018). Pengaruh Media Audio Visual Terhadap Hasil Belajar Siswa Pada Materi Jenis-Jenis Pekerjaan Di Sekolah Dasar. Pedadidaktika: Jurnal Ilmiah Pendidikan Guru Sekolah Dasar, 5(2), 308-316.

Sajawandi, L., \& Rosalina, A. (2020). Peningkatan Kemampuan Membaca Permulaan Melalui Media Buku "Membaca Itu Mengasyikkan" Di Tk Plus Al Burhan Kecamatan Buaran Kabupaten Pekalongan. Tematik: Jurnal Pemikiran Dan Penelitian Pendidikan Anak Usia Dini, 6(2), 62. Https://Doi.Org/10.26858/Tematik.V6i2.15088

Soetjiningsih. (2012). Tumbuh Kembang Anak. Egc.

Srijatun, S. (2017). Implementasi Pembelajaran Baca Tulis Al Qur'an Dengan Metode Iqra Pada Anak Usia Dini Di Ra Perwanida Slawi Kabupaten Tegal. Nadwa, 11(1), 25. Https://Doi.Org/10.21580/Nw.2017.11.1.1321

Sugiyono. (2016). Metode Penelitian Kombinasi (Mix Methode). Alfabeta.

Suyadi, \& Ulfah, M. (2015). Konsep Dasar Paud. Remaja Rosda Karya.

Tanu, I. K. (2019). Pentingnya Pendidikan Anak Usia Dini Agar Dapat Tumbuh Dan Berkembang Sebagai Generasi Bangsa Harapan Di Masa Depan. Adi Widya: Jurnal Pendidikan Dasar, 2(2), 19. Https://Doi.Org/10.25078/Aw.V2i2.960

Trimantara, H., \& Mulya, N. (2019). Mengembangkan Bahasa Anak Usia 4-5 Tahun Melalui Alat Permainan Edukatif Puzzle. Al-Athfaal: Jurnal Ilmiah Pendidikan Anak Usia Dini, 2(1), 25-34. Https://Doi.Org/10.24042/Ajipaud.V2i1.4553

Wulansuci, G. (2021). Stres Akademik Anak Usia Dini: Pembelajaran Calistung Vs. Tuntutan Kinerja Guru. Golden Age: Jurnal Ilmiah Tumbuh Kembang Anak Usia Dini, 6(2), 79-86. Https://Doi.Org/10.14421/Jga.2021.62-03

Yunitasari, R., \& Hanifah, U. (2020). Pengaruh Pembelajaran Daring Terhadap Minat Belajar Siswa Pada Masa Covid 19. Edukatif: Jurnal Ilmu Pendidikan, 2(3), 232-243. Https://Doi.Org/10.31004/Edukatif.V2i3.142 